\title{
The Influence of Short-Term Overseas Internship on English Learners' Self-Efficacy and Intercultural Communication Apprehension
}

\author{
Yangming Jing $^{1}$ \& Jianying Zhang $^{1}$ \\ ${ }^{1}$ Business English Department, Dalian Neusoft University of Information, No. 8 Software Park Road, Dalian, \\ China
}

Correspondence: Yangming Jing, Business English Department, Dalian Neusoft University of Information, No. 8 Software Park Road, Dalian, China.

Received: June 14, 2019 Accepted: August 4, 2019 Online Published: August 6, 2019

doi: 10.5539/elt.v12n9p6 URL: https://doi.org/10.5539/elt.v12n9p6

\begin{abstract}
There are more choices of overseas internship program with the increasing international communication. As an international language, English plays an important role in overseas internship program. The influence of short-term overseas internship is worthy of deep study. This study was designed to explore the possible influence of short-term Disney College Internship on interns' self-efficacy and intercultural communication apprehension. Questionnaires and follow-up interview were used to collect data. The results show that the internship experience has enhanced interns' intercultural self-efficacy and lowered their intercultural communication apprehension.
\end{abstract}

Keywords: self-efficacy, intercultural communication apprehension, short-term overseas internship

\section{Introduction}

Studying abroad or working abroad provides an ideal language learning environment for foreign language learners. With the increasing international communication, more and more short-term internship programs are available. It is a easy access for researchers to study on oversea study or international programs. Many researchers examined the effects of studying abroad on English learners' self-awareness, intercultural communication apprehension, intercultural sensitivity and intercultural communicative competence (e.g., Kang, 2014; Williams, 2005; Wu, Liu, Lang, \& Rong, 2017).

Disney College Internship program is an exchange training program that integrates American college classroom learning and Fortune 500 internships. The program is supported by the United States Act. The program selects outstanding students of different English proficiency from Chinese universities, who are sent to the United States as $\mathrm{J}-1$ (A $\mathrm{J}-1$ visa is a non-immigrant visa issued by the United States to research scholars, professors and exchange visitors participating in programs that promote cultural exchange, especially to obtain medical or business training within the U.S.) exchange students. All participants at different English levels need to study at American universities for a period time first. Then, in the next 6 months, they will go to Walt Disney World in Orlando, Florida, for a paid internship and a course taught by a teacher at the University of Disney. As a former program participant, the author knows the flow of the program very well, and also had intercultural experiences and gained research inspiration from it.

Much of the research on overseas programs (Behrnd \& Porzelt, 2012; Byram, 1997) has focused on cultural shock or intercultural communication competence, and mainly about studying abroad. There is little research on short-term overseas internship program. The study is a 6-month longitudinal research on participants of Disney College Internship Program, aiming at providing advice for future program participants in language learning, oversea survive ability improvements and culture shock as well as reference for international exchange program working staff.

Based on the author's own experience, this study is designed to explore the influence of short-term overseas internship on English learners from two perspectives: self-efficacy and intercultural communication apprehension. The results of the study have certain theoretical enlightenment and practical significance for future research in the related field. 


\section{Literature Review}

\subsection{Self-Efficacy}

Self-efficacy was first introduced by Bandura in 1977. Self-efficacy can be defined as the belief that one can successfully carry out the behavior required to produce a particular outcome (1997). He believes that most previous researchers focused on people's knowledge acquisition or behavioral response, but neglected the process of interaction between knowledge and behavior. Therefore, Bandura put forward the concept of "self-efficacy", which holds that people's judgment of their own ability plays a major role in the self-regulation system. In 1982, Bandura formally put forward the Self-Efficacy Theory.

Bandura indicated that self-efficacy is the self-perception of an individual's ability to accomplish a given task (1994). The formation and changes of self-efficacy are influenced by the following five sources of information: mastery experience, vicarious experience, social persuasion, physiological state and emotional state. Positive emotions, such as confidence, can improve a person's sense of self-efficacy. In this study, we mainly focus on the degree of confidence of the interns in the program.

\subsection{Intercultural Communication Apprehension}

Intercultural communication apprehension was defined as the fear or anxiety associated with either real or anticipated communication apprehension with people from different groups, especially cultural and/or ethnic groups (Neuliep \& McCroskey, 1997).

\subsection{Previous Studie}

Concerning self-efficacy study, most researchers choose to study the relationship between self-efficacy and cross-cultural adaptation. Some researchers indicate that people with higher self-efficacy are more likely to be relaxed in cross-cultural interaction (Fan \& Mak, 1998). In a longitudinal study by Hechanova-Alampay et al. (2002), researchers found that international students' self-efficacy is positively correlated with their adaptation to the new cultural context for studying abroad. Harrison et al. support that people with high self-efficacy are significantly better than those with low self-efficacy in general cross-cultural adaptation and work adaptation (Harrison et al., 1996). In Gao et al.'s study (2012), it is founded that language and knowledge have significant positive effect on students' self-efficacy. Researchers generally focus on the impact or extent of self-efficacy on cross-cultural adaptation.

According to Wang (2004), the lack of understanding of foreign countries' society, education system and background knowledge will lead to the intercultural communication apprehension. Intercultural communication apprehension is influenced by different cultural background, and students from collectivist culture country have higher intercultural communication apprehension than individualistic culture country's students (e.g., Wu et al., 2017; Pan, 2007). Wu, et al. found that after studying abroad for a short time, the level of intercultural communication apprehension apprehension can be significantly reduced (2017).

Guided by the research objective, there are two research questions: (1) what are differences between self-efficacy before and after program; (2) what are differences between intercultural communication apprehension before and after program.

\section{Methodology}

This study takes Chinese interns of Walt Disney World program as the research subject. Mixed research methods are use to collect data, with questionnaire being the main method and interview playing a supplementary role.

\subsection{Participants}

\subsubsection{Questionnaire}

In this study, a total of 54 interns participated in the questionnaire in the first phase. There are 42 participants were working at Disney and 12 participants attended 2017 autumn program. And 44 interns took the questionnaire in the second phase, 32 participants were working at Disney and 12 participants attended previous program.

A total of 30 valid questionnaires are sorted out. The 30 participants are undergraduate students from different Chinese and oversea universities. Among the 30 participants, nine have lived or traveled in America, two of whom have lone-term overseas studying experiences. One grew up in Spain since 12 years old and one studied in France for 4 years. The 30 participants major in English, Business English, Tourism Management, hotel management, International Business and so on. Twelve among 30 participants passed TEM 4 (Test for English Majors Grade Four). There are 3 males and 27 females. The subjects are between 18 and 23 years old. 


\subsubsection{Interview}

Five participants (interviewees were named as Z, W, A, Q and L) were invited to the face-to-face interview. Five interviewees all come from the same university and same grade. Four of them major in Business English and one of them major in English. All of them have different English proficiency and academic performance. All interviewees are female.

\subsection{Instruments}

\subsubsection{Questionnaire}

Two questionnaires were designed to examine the change of participants' self-efficacy and intercultural communication apprehension before and after the internship. Both questionnaires consist of three parts, investigation interns' personal information, their self-efficacy and intercultural communication apprehension in different phases. The questions are listed as below:

Table 1. Information about questionnaire

\begin{tabular}{ll}
\hline & Questions \\
\hline & Name; Gender; \\
& English proficiency before program; \\
& Experience of living or studying in America; \\
& Job position at Walt Disney world; \\
& Average usage of English in the work place \\
Basic information & English listening confidence level; \\
& Oral English confidence level, English listening issues in the \\
& workplace; \\
& Oral English issues in the workplace; \\
& Activities in the break room; \\
& Conflicts with colleagues from different cultures; \\
Self-efficacy & Initiative to seek help from leaders to solve problems in \\
& workplace \\
& Do or do not afraid to communicate with others in English \\
& How long does participant adapt to job position? \\
& Do or do not face problems existing in workplace with positive \\
Intercultural communication apprehension & working attitude? \\
\hline
\end{tabular}

Table 2. Information about questionnaire dimension

\begin{tabular}{lll}
\hline & Questionnaire in the first phase & Questionnaire in the second phase \\
\hline Personal information & 1,2 & 1,2 \\
English Proficiency & 3 & 4 \\
Job position & 5 & \\
Working hours & 11 & $12-21$ \\
Self-efficacy & $13-22$ & $22-27$ \\
Intercultural communication apprehension & $23-28$ & \\
\hline
\end{tabular}

\subsubsection{Interview}

The purpose of interview is to explore the underlying cause of various differences and changes in quantitative analysis. The interview questions mainly concern (1) What were interns' two job positions and how do they think about their job position? (2) How do they think about the change between two job position and work content? (3) 
Were they very confident about their English when they first arrived in the United States? (4) How did they adjust themselves to integrate into local life; (5) What did they usually do during holiday or day off; (6) What are Interns' opinions about the internship and so on.

\subsection{Procedures}

In this study, the questionnaires are distributed through sojump website. The first questionnaire was conducted two weeks after the intern took the job, and the second questionnaire was carried out within one week after the program was completed. Both two questionnaires were sent into individual or group chat through Wechat social media.

Interview took place the day after participants returned to university, and was conducted by the author. The whole interview was recorded and the voice data was were transferred to text.

\subsection{Data Analysis}

In this study, after sorting out the results of the questionnaire, all data were submitted to SPSS 16.0. T-test, regression analysis, and correlation analysis were conducted.

\section{Results}

\subsection{Changes of Self-Efficacy}

Influenced by different factors, interns' self-efficacy could change or could not change before and after program. Paired-Samples t-test was conducted to test the change of interns' self-efficacy before and after program, the results are shown as follows:

Table 3. Paired samples test: self-efficacy

\begin{tabular}{|c|c|c|c|c|c|c|c|c|c|}
\hline & & Paired I & rences & & & & & & \\
\hline & & S & $\mathrm{S} D$ & S.E. & $\begin{array}{l}95 \% \\
\text { Interval } \\
\text { Difference }\end{array}$ & $\begin{array}{l}\text { Confidence } \\
\text { of the }\end{array}$ & & & $\begin{array}{l}\text { Sig. } \\
\text { (2-tailed) }\end{array}$ \\
\hline & & Mean & S.D. & & Lower & Upper & $\mathrm{t}$ & dt & \\
\hline Pair 1 & I13A \& I12B & .53333 & .62881 & .11480 & -.76813 & -.29853 & -4.646 & 29 & .000 \\
\hline Pair 2 & I14A \& I13B & .56667 & .62606 & .11430 & -.80044 & -.33289 & -4.958 & 29 & .000 \\
\hline Pair 3 & $\mathrm{I} 21 \mathrm{~A} \& \mathrm{I} 20 \mathrm{~B}$ & .06667 & .44978 & .08212 & -.10128 & .23462 & .812 & 29 & .423 \\
\hline
\end{tabular}

Note. I13A refers to the 13th question items in the first questionnaire, which is"What is your English listening confidence level at the earlier stage of internship?"; I12B refers to the 12th question in the second questionnaire, which is "What is your English listening confidence level at present?"; I14A refers to the 14th question items in the first questionnaire which is "What is your oral English confidence level at the earlier stage of internship?"; I13B refers to 13th question items in the second questionnaire, which is "What is your oral English confidence level at present?"; I21A refers to the 21th question items in the first questionnaire, which is "Will you take the initiative to ask help from your leader when you meet problems in workplace or have conflicts with colleagues?"; I20B refers to the 20th question items in the second questionnaire, which is "Will you take the initiative to ask help from your leader when you meet problems in workplace or have conflicts with colleagues?".

\subsection{Changes of Intercultural Communication Apprehension}

Table 3. Paired samples test: intercultural communication apprehension

\begin{tabular}{|c|c|c|c|c|c|c|c|c|c|}
\hline & & Paired D & erences & & & & & & \\
\hline & & & & & $\begin{array}{l}95 \% \\
\text { Interval } \\
\text { Difference }\end{array}$ & $\begin{array}{l}\text { Confidence } \\
\text { of the }\end{array}$ & & & Sig. \\
\hline & & Mean & S.D. & Mean & Lower & Upper & $\mathrm{t}$ & dt & \\
\hline Pair 1 & I23A \& I22B & -.56667 & .56832 & .10376 & -.77888 & -.35445 & -5.461 & 29 & .000 \\
\hline
\end{tabular}




$\begin{array}{llllllllll}\text { Pair 2 } & \text { I26A \& I25B } & -.36667 & .61495 & .11227 & -.59629 & -.13704 & -3.266 & 29 & .003 \\ \text { Pair 3 } & \text { I28A \& I27B } & -.83333 & .59209 & .10810 & -1.05442 & -.61224 & -7.709 & 29 & .000\end{array}$

Note. I23A refers to the 23th question items in the first questionnaire, which is "Are you afraid to communicate with others in English when you start your work?"; I22B refers to the 22th question items in the second questionnaire which is "Are you afraid to communicate with others in English at present?"; I26A refers to the 26th question items in the first questionnaire, which is "Do you face problems existing in workplace with a positive attitude?"; I25B refers to the 25th question items in the second questionnaire, which is "Will you face problems existing in workplace with a positive attitude if you have a new overseas internship?"; I28A refers to the 28th question items in the first questionnaire, which is "Do you feel lonely when you first arrive in the United States?"; I27B refers to the 27th question items in the second questionnaire, which is "Do you still feel lonely at present in the United States?"

\section{Discussion}

\subsection{Changes of Self-Efficacy}

The result of changes of self-efficacy shows that interns' self-efficacy (English listening confidence level and oral English confidence level) has been significantly improved after program. According to interviewees, long-term communication with people in English, interns' listening and speaking skills were constantly improved. At Walt Disney World, participants are more likely to communicate with colleagues and customers, they complete given task well, and feel more confident compared with earlier stage. "I did the job of food and beverage service first and then moved to the merchandise sector" one of interviewees said "at the beginning of program, my trainer is the only person I can talk to, I am afraid to speak aloud or answer customers' questions." Participant W has the same opinions, "they speak so fast that I cannot totally understand and I am afraid that others may laugh at my English."

Direct communication with Americans and understanding of program are main factors to increase intercultural self-efficacy in international internship program. Communicating with locals directly increases interns' self-efficacy. Though long-term contact with native speakers, interns' oral and listening skills have improved. They feel more and more confident about their working ability or English Proficiency. Zimmermann (1995) mentioned that in talk with American students was the single most important factor in perceptions of communication competency and adjusting to American life. Students are willing to spend weekends cooking or socializing with Americans. Meanwhile, understanding of internship or program is a major factor in increasing intercultural self-efficacy. As is mentioned above, there is a gap between interns' expectation and reality. "We thought we can spend a easy and comfortable intern life at Disney but we have to do lots of physical work and have a long shift each day". Participant A said "we had a general training before program, we knew general job position rather than specific work". If interns have a specific understanding of their internship or entire program, they may be more psychologically prepared to deal with it, and their self-efficacy will increase with it.

It is worth noting that the intern's initiative of talking to leader about working problems has not changed. Compared with the previous period of internship, interns are not more willing to take the initiative to find leaders to solve problems existing in workplace. According to the interview, interns think they are different from their leaders and there is a long distance between them. They try to solve the problems existing in workplace by themselves rather than leaders. "The education I received since I was young make me feel like that I should not be looking for a leader to solve my problem." Student Q said. This is power distance issue which is often studied in many cross-cultural studies.

\subsection{Changes of Intercultural Communication Apprehension}

It is found from table 4.2 that interns' intercultural communication apprehension has decreased. It is concluded from interview that work pressure and gap between reality and expectation led to students' intercultural communication apprehension. At the earlier stage, interns were not well suited to new work environment and working shifts. High working intensity and difficulty put a lot of pressure on them. They do not have enough time to socialize and make new friends during the earlier few weeks. "We have two days off each week, and we choose to get into park for fun or have party with friends. Sometimes we would like to stay at home to relax." Students gradually get used to this kind of life and have chances to enjoy the internship program. Meanwhile, some students participate program for making money and escaping classes from university but heavy work and assignments are not what they expect. 
Social support is one of the factors to decrease intercultural communication apprehension in international internship program. As Chen et al. (2003) mentioned in a study, social support from families or friends is an external factor that affects cross-cultural adaptation. Interns felt lonely when they get into an unfamiliar environment, and they choose to contact with families through Wechat video call. Friends and families conform or encourage them, and with such support, they feel less intercultural communication apprehension. "Thanks to technological advances, the 12-hour jet lag between China and America dose not pose a major problem, when we get off work, our parents or friends get up and we have time and chances to communicate" students L said.

\section{Conclusion}

\subsection{Major Findings}

The purpose of this study is to discuss the influence of short-term overseas internship on English learners' self-efficacy and intercultural communication apprehension. The major finding of this study is that interns' self-efficacy has been improved and intercultural communication apprehension has been reduced before and after overseas internship program.

\subsection{Limitations}

This study also has some limitations. First of all, the author did not conduct an oral English assessment for participants before and after Disney overseas internship program, which suggested to be tested in the future research. Meanwhile, the author does not follow up and observe the participants after internship.

\subsection{Implications}

The current research results have certain theoretical enlightenment and practical guiding significance to the future research. It provides some references and thoughts for studying the influence of short-term overseas internship on English learners' self-efficacy and intercultural communication apprehension. For international educators, better understanding the interns' change is necessary to design a better exchange program.

\section{References}

Allen, H. W., \& Herron, C. (2003). A Mixed-Methodology Investigation of the Linguistic and Affective Outcomes of Summer Study Abroad. Foreign Language Annals, 36(3), 370-385. https://doi.org/10.1111/ j.1944-9720.2003.tb02120.x

Allen, W. E. (2019). Pursuing Cross-Cultural Pedagogical Success in China. International Journal of Contemporary Education, 2(1), 43. https://doi.org/10.11114/ijce.v2i1.4079

Bandura, A. (1977). Self-efficacy: Toward a unifying theory of behavioral change. Psychological Review, 84(2), 191-215. https://doi.org/10.1037//0033-295x.84.2.191

Bandura, A. (1997). Self-Efficacy. Encyclopedia of Health and Behavior. https://doi.org/10.4135/9781412952576.n182

Behrnd, V., \& Porzelt, S. (2012). Intercultural, Competence and Training Outcomes of Students with Experiences Abroad. International Journal of Intercultural Relations, 36(2), 213-223. https://doi.org/10.1016/ j.ijintrel.2011.04.005

Byram, M. (1997). Teaching and Assessing Intercultural Communicative Competence (pp. 121-126). Clevedon: Multilingual Matters.

Chen, H., Che, H. S., \& Zhu, M. (2003). Kua Wen Hua Shi Ying Ying Xiang Yin Su Yan Jiu Shu Ping. Advances In Psychological Science, 11(6), 704-710.

Fan, C., \& Mak, A. S. (1998). Measuring Social Self-efficacy in Culturally Diverse Student Population. Social Behavior and Personality, 26(2), 131-144. https://doi.org/10.2224/sbp.1998.26.2.131

Gao, J., Liu, X. D., Ran, Z. Z., Wang, H., Wang, Y., \& Zhang, S. (2012). Lai Hua Liu Xue Sheng Kua Wen Hua Shi Ying Xing He Zi Wo Xiao Neng Gan Ying Xiang Yin Su De Tan Tao- Ya Zhou He Fei Zhou Lai Hua Liu Xue Sheng De Bi Jiao. Paper Presented at the Ninth International Conference on Chinese Medical Specialists and Psychologists. Liaoning, China. Abstract retrieved from http://navi.cnki.net/KNavi/ DPaperDetail?pcode $=$ CIPD\&lwjcode $=$ GJXL201207001\&hycode $=014997 \#$

Harrison, J. K., Chadwick, M., \& Scales, M. (1996). The relationship between cross-cultural adjustment and the personality variables of self-efficacy and self-monitoring. International Journal of Intercultural Relations, 20(2), 167-188. https://doi.org/10.1016/0147-1767(95)00039-9

Hechanova-Alampay, R., Beehr, T. A., Christiansen, N. D., \& Van Horn, R. K. (2002). Adjustment and Strain 
among Domestic and International Student Sojourners. School Psychology International, 23(4), 458-474. https://doi.org/10.1177/0143034302234007

Kang, Dae-Min. (2014). The Effects of Study-abroad Experiences on EFL Learners' Willingness to Communicate Speaking Abilities, and Participation in Classroom Interaction. System, 42, 319-332. https://doi.org/10.1016/j.system.2013.12.025

Neuliep, J. W., \& McCroskey, J. C. (1997). The development of intercultural and interethnic communication apprehension scales. Communication Research Reports, 14(2), 145-156. https://doi.org/10.1080/088240997 09388656

Neuliep, J. W. (2012). The Relationship among Intercultural Communication Apprehension, Ethnocentrism, Uncertainty Reduction, and Communication Satisfaction during Initial Intercultural Interaction: An Extension of Anxiety and Uncertainty Management (AUM) Theory. Journal of Intercultural Communication Research, 41(1), 1-16. https://doi.org/10.1080/17475759.2011.623239

Neuliep, J. W. (2017). Intercultural Communication Apprehension. The International Encyclopedia of Intercultural Communication, 1-5. https://doi.org/10.1080/17475759.2011.623239

Pan, S. (2007). Intercultural Communication Apprehension, Ethnocentrism and Their Relationship with Gender: A Cross-cultural Comparison between the US and China // Annual Meeting of the NCA 93rd Annual Convention.

Wang, Y. (2004). Pursuing Cross-cultural Graduate Education: A Multifaceted Investigation. International Education, 33(2), 52-72.

Williams, T. R. (2005). Exploring the Impact of Study Abroad on Students' Intercultural Communication Skills: Adaptability and Sensitivity. Journal of Studies in International Education, 9(4), 356-371. https://doi.org/10.1177/1028315305277681

Wu, J. S., Liu, Q., Lang, J. G., \& Rong, Y. C. (2017). The Effects of Short-term Study-abroad Context and Language Proficiency. Foreign Languages and Their Teaching, 3, 89-99.

Zimmermann, S. (1995). Perceptions of intercultural communication competence and international student adaptation to an American campus. Communication Education, 44(4), 321-335. https://doi.org/10.1080/03634529509379022

\section{Copyrights}

Copyright for this article is retained by the author(s), with first publication rights granted to the journal.

This is an open-access article distributed under the terms and conditions of the Creative Commons Attribution license (http://creativecommons.org/licenses/by/4.0/). 